\title{
Survey of Eight Hormone Tests Used by Clinical Laboratories in Korea
}

\author{
Rihwa Choi ${ }^{1,2}$ and \\ Hyung-Doo Park ${ }^{1}$ \\ ${ }^{1}$ Department of Laboratory \\ Medicine and Genetics, \\ Samsung Medical Center, \\ Sungkyunkwan University \\ School of Medicine, Seoul; \\ ${ }^{2}$ Department of Laboratory \\ Medicine, Green Cross \\ Laboratories, Yongin, Korea
}

\author{
Corresponding author: \\ Hyung-Doo Park \\ Department of Laboratory \\ Medicine and Genetics, Samsung \\ Medical Center, Sungkyunkwan \\ University School of Medicine, \\ 81 Irwon-ro, Gangnam-gu, Seoul \\ 06351, Korea \\ Tel: $+82-2-3410-0290$ \\ Fax: +82-2-3410-2719 \\ E-mail: nayadoo@hanmail.net
}

pISSN: 2384-2458

elSSN: 2288-7261

\begin{abstract}
Background: This study aimed to investigate the current statuses of eight hormone tests (testosterone, estradiol, prolactin, progesterone, luteinizing hormone, follicle-stimulating hormone, parathyroid hormone, and thyroglobulin) used by clinical laboratories in Korea.

Methods: From November 1 to December 31, 2016, we surveyed 300 laboratories that participated in the regular proficiency survey program administered by the Korean Association of Quality Assurance for Clinical Laboratory. The survey comprised a questionnaire designed to address factors related to these hormone tests, including the measurement methods, instruments, test numbers per month, turnaround times, reporting units and ranges, reference ranges, and internal or external quality control methods.

Results: Fifty-four (18.0\%) of 300 laboratories replied to the survey questionnaire. Each laboratory performed hormone analyses that used variable instruments, commercial kits, and calibrators. The test numbers per month, turnaround times, and reporting units (particularly for testosterone) varied among laboratories. Most laboratories used reference intervals that had been transferred from other references and were verified using in-house samples. Many laboratories that assessed luteinizing hormone, follicle-stimulating hormone, and parathyroid hormone levels did not participate in the proficiency survey program conducted by The Korean Association of Quality Assurance for Clinical Laboratory.

Conclusions: We hope that the results of this study, which investigated the status of hormone testing at Korean diagnostic laboratories, will facilitate improvements in the quality of hormone testing and promote the development of guidelines for testing.
\end{abstract}

(J Lab Med Qual Assur 2017;39:124-131)

Key Words: Surveys and questionnaires, Laboratory proficiency testing, Clinical laboratory services, Hormones

Received February 22, 2017, Revision received March 26, 2017, Accepted April 3, 2017

\section{서론}

호르몬검사는 각종 호르몬질환의 진단뿐 아니라 각종 질 환의 치료반응을 모니터링하는 데 있어 반드시 필요한 임상 적 중요성이 높은 검사이다. 호르몬검사는 여러 가지 호르몬 관련 질환의 진단 및 모니터링 등에 필수적인 검사이지만, 아 직까지 검사방법과 결과가 표준화되거나 일치화되어 있지 않다. 방사성면역측정법(radioimmunoassay), 화학발광법 (chemiluminescent) 등의 면역측정법을 이용한 검사부터 액 체 크로마토그래피나 가스 크로마토그래피 등과 결합한 질량 분석기를 이용한 검사방법 등 다양한 방식으로 측정할 수 있 다. 이질적인 검사방법들 간뿐만 아니라 동일한 검사방법 내
에서도 측정 장비나 시약에 따라 검사결과가 다양하여 정확도 나 정밀도 등 검사성능에 대한 문제 제기가 다양하게 보고되 고 있다[1]. 특정 질환에서는 임상적으로 매우 중요한 호르몬 측정치의 경도 변화가 임상적 판단에 결정적인 영향을 미치는 경우가 있기 때문에 미국 질병예방센터(Centers for Disease Control and Prevention, $\mathrm{CDC}$ )나 Endocrine Society 등의 국제적 기관에서는 신뢰도가 높지 않은 호르몬검사를 임상적 으로 사용하는 것에 대한 우려를 표시하고 있으며, 검사 일치 화(harmonization)에 대한 국제적 질 관리프로그램의 필요성 을 강조하고 있다[1]. 그러나 대부분의 국내 임상검사실에서 시행하는 호르몬검사는 측정방법 및 결과가 검사실 간에 매우 다양한 차이를 보이고 있으며, 정확하고 신뢰성 있는 검사를 
위한 기관별 호르몬검사에 대한 국내 현황조사가 미흡하여 각 호르몬검사의 참고자료로 활용될 수 있는 기초 참고자료가 필 요한 실정이다. 이 연구의 목적은 대한임상검사정도관리협회 신빙도조사에 참여하고 있는 회원기관을 대상으로 국내 임상 검사실에서 시행되는 8종의 호르몬 - testosterone, estradiol (E2), prolactin, progesterone, luteinizing hormone (LH), follicle-stimulating hormone (FSH), parathyroid hormone (PTH), thyroglobulin -검사들에 대하여 각 검사방법 및 특성 을 조사하고 분석하여 향후 각 검사실에서 호르몬검사의 질 향 상을 위한 참고자료로 활용될 수 있는 기초자료를 제시하고자 하였다.

\section{재료 및 방법}

\section{1. 대상 및 기간}

2016년 11월 1일부터 12월 31일까지 대한임상검사정도관리 협회 회원기관을 대상으로 2016년 대한임상검사정도관리협회 의 호르몬검사 신빙도조사사업을 신청한 기관 중 300 개 기관 을 선정하여 설문조사를 시행하였다.

\section{2. 호르몬검사 현황에 관한 설문조사}

'2016년도 호르몬검사 현황 설문조사지’를 작성하여 대상기 관에 이메일을 보내고 회신결과를 받았다. 설문조사지 내용은 각 8종 호르몬의 측정에 사용되는 검사방법, 검사장비, 월간 검사 건수, 목표 보고소요시간(turnaround time) 기준, 결과 보고단위, 보고범위, 참고범위, 내부 및 외부정도관리방법 등 에 대한 내용을 포함하였다. 각 호르몬검사에 대한 현황을 파 악하여 월간 검사 건수, 결과 보고단위, 참고범위, 내부 및 외 부 정도관리에 대한 분석은 개별 문항에 대해 응답한 기관의 수를 분모로 분석하였다.

\section{결과}

\section{1. 검사방법}

300 기관 중 54 기관(18.0\%)으로부터 설문조사 회신을 받았 다. 설문에 응답한 54 기관 중 전체 호르몬검사를 핵의학과에 서 시행한다고 응답한 2기관과 8종 모두 시행하지 않고 있다 고 응답한 1 기관은 분석에서 제외하여 총 51 기관을 대상으로 결과를 분석하였다.

분석대상 51 기관 중 44 기관은 병원의 진단의학검사실 이었으며, 7 기관은 전문수탁검사기관이었다. 호르몬검 사를 시행 중이라고 응답한 기관의 수는 다양하였는데, testosterone은 36 기관, estradiol은 43기관, prolactin은 39 기관, progesterone은 14 기관, $\mathrm{LH}$ 는 42 기관, $\mathrm{FSH}$ 는 43기관, parathyroid hormone은 46기관, 그리고 thyroglobulin은 36 기관에서 시행 중이라고 응답하였다.

51기관 중 호르몬검사방법의 분석원리(enzyme immunoassay, chemiluminescent microparticle immunoassay, radioimmunoassay 등)에 대해 응답한 대부분의 기관들은 8 종의 호르몬검사에 대해 1 가지 방법으로 검사를 시행하고 있 었고, 1 기관에서는 thyroglobulin을 제외한 나머지 7종 호르몬 에 대해 2 가지 이상의 방법으로 검사한다고 보고하였다. 이 외 testosterone과 $\mathrm{FSH}$ 의 경우 각각 1 기관에서 2 가지 이상의 방 법으로 시행한다고 보고하였다. 2 가지 이상의 방법으로 검사 한다고 보고한 기관들은 대표적인 분석장비를 기준으로 응답 하였다.

Testosterone과 progesterone의 경우 각각 1 기관에서 radioimmunoassay를 이용한다고 하였고, 나머지 기관들은 모두 8종 호르몬에 대해 chemiluminescent immunoassay, electrochemiluminescent immunoassay 등의 면역측정법을

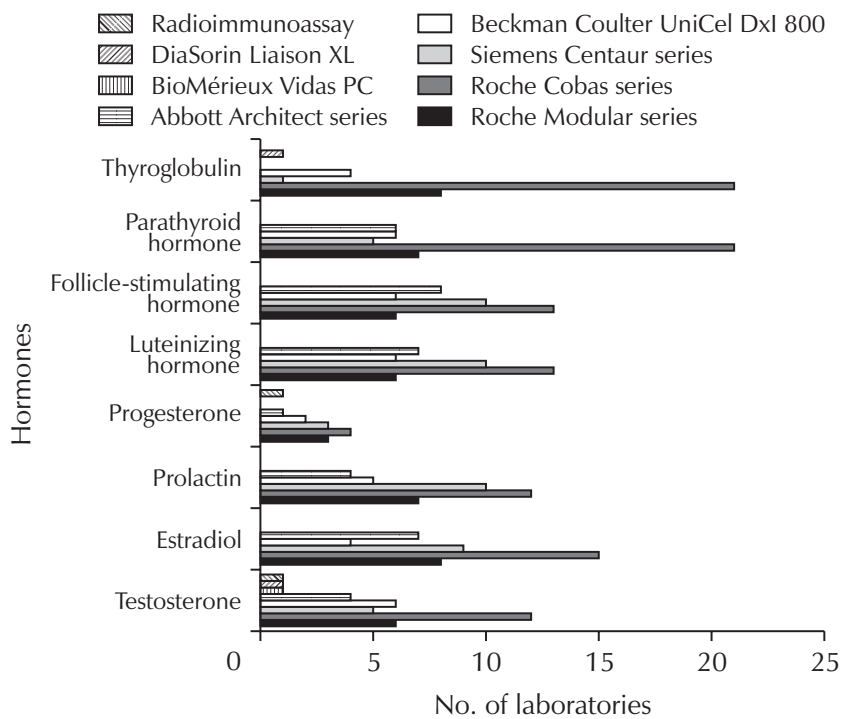

Fig. 1. Equipment used to measure the levels of eight hormones at clinical laboratories in Korea. The following test was used: Radioimmunoassay \& Roche Cobas/Modular series (Roche Diagnostics GmbH, Mannheim, Germany), DiaSorin Liaison XL (DiaSorin, Stillwater, MN, USA), BioMérieux Vidas PC (BioMérieux, Marcy l'Etoile, France), Abbott Architect series (Abbott Diagnostics, Abbott Park, IL, USA), Beckman Coulter UniCel DxI 800 (Beckman Coulter Inc., Brea, CA, USA), and Simens Centaur series (Simens Healthcare Diagnostics, Tarrytown, NY, USA). 
이용한다고 응답하였다. 매우 다양한 분석장비들이 사용되고 있었지만, 질량분석법으로 검사하는 기관은 없었다(Fig. 1).

\section{2. 월간 검사 건수 및 목표 보고소요 시간}

설문에 응답한 모든 기관들이 주 1 회 이상 검사하고 있었는 데, 대부분 $83.3 \%-95.6 \%)$ 의 기관에서 호르몬검사를 매일 시 행하였으며, 호르몬검사 건수는 월 100건 미만부터 500건 이 상까지 기관별로 매우 다양하였다. 호르몬검사의 보고소요시 간은 기관별로 매우 다양하였으며, 호르몬검사를 시행중인 기 관 중 $13.9 \%-26.1 \%$ 는 2 시간 이내 결과보고를 하였고, $7.1 \%$ $16.7 \%$ 의 기관은 보고소요시간 기준이 24 시간을 초과하였다.

\section{3. 결과 보고단위 및 보고범위}

응답기관 중 testosterone을 제외한 나머지 7종 호르몬에 대해서 대부분(94.9\%-100.0\%)의 기관들이 conventional unit으로 보고한다고 응답하였다. Testosterone의 경우 기 관들 간 보고단위가 매우 다양하였는데, 5 기관(13.9\%)에 서 conventional unit으로, 1기관(2.8\%)에서 International System of Units (SI) unit으로 보고한다고 응답하였고, 나 머지 $77.8 \%$ 의 기관들은 conventional unit이나 SI unit이 아 닌 다른 보고단위를 이용하고 있었다(Table 1). 응답한 기관들 중 동일한 보고단위를 이용하는 기관들의 분석 및 보고범위는 Table 2 와 같다.

\section{4. 참고범위}

참고범위는 testosterone과 estradiol의 경우 1 기관, prolactin과 progesterone의 경우 각각 2 기관씩, $\mathrm{LH}$ 는 3 기관, $\mathrm{FSH}$ 는 5 기관을 제외한 모든 기관들이 성별을 구분한 참고범 위를 적용하고 있었다. Parathyroid hormone의 경우 응답기 관의 $23.4 \%$ (47기관 중 11 기관)에서만 성별을 구분한 참고범 위를 적용하고 있었고, thyroglobulin의 경우는 5 기관만 성별 을 구분한 참고범위를 적용하고 있었다. 연령에 따른 참고범 관들이 연령에 따라 참고범위를 나누지 않고 보고하고 있었고, 나머지 호르몬들은 연령에 따라 참고범위를 구분하거나 구분 하지 않고 보고하는 정도가 기관마다 다양하였다.

참고범위는 estradiol과 parathyroid hormone의 경우 각각 2 기관, $\mathrm{LH}$ 와 $\mathrm{FSH}$ 의 경우 각각 1 기관, thyroglobulin의 경우 3 기관은 자체 설정한 참고범위를 적용하고 있었고, 이들 기관 을 제외한 나머지 기관은 모두 외부 참고범위를 도입하여 적용 하고 있었다. 자체 설정한 참고범위를 적용하는 경우 1 기관에 서만 119 명 이하의 결과를 이용하여 자체 설정하였다고 응답 위 구분은 thyroglobulin의 경우만 검사한다고 응답한 모든 기

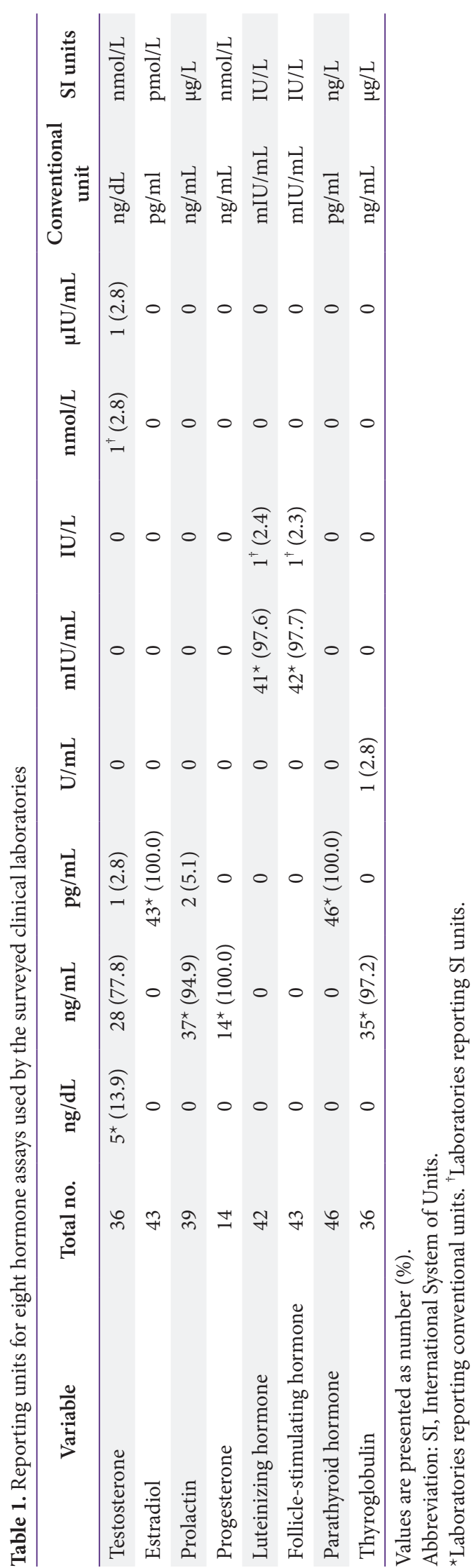




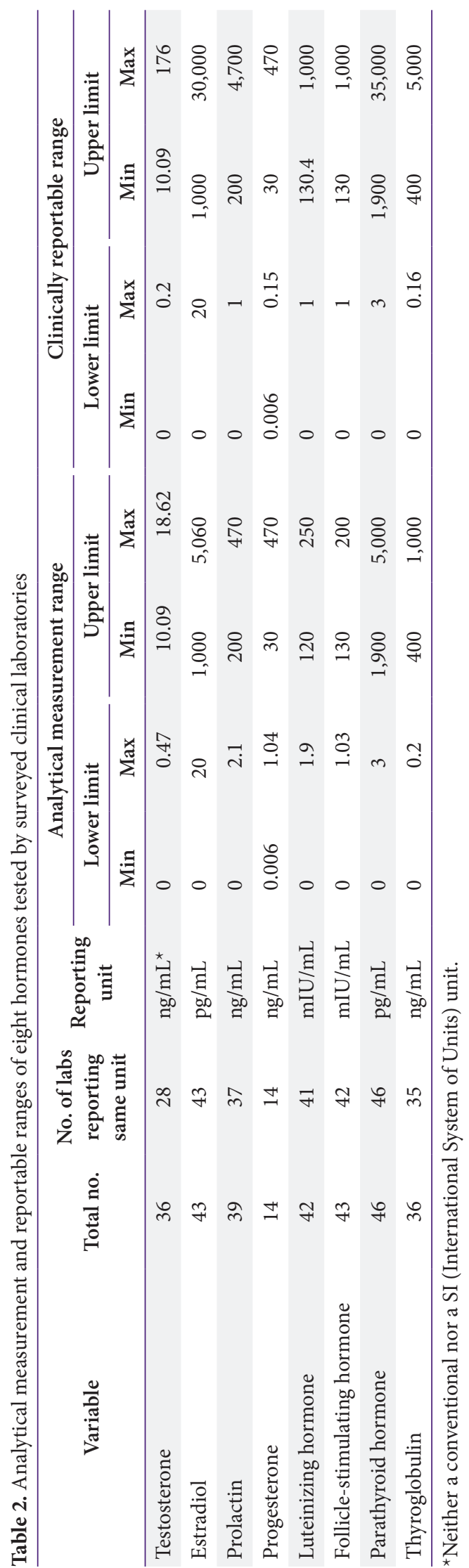

하였고, 나머지 기관들은 120-145명 또는 146-209명의 결과 를 이용하여 자체 설정한 것으로 응답하였다.

외부 참고범위를 도입한 기관들 중 19 명 이하의 결과를 이 용하여 외부 참고범위를 검증하였다고 응답한 1 기관을 제외한 나머지 모든 기관은 20 명 이상의 결과를 이용하여 검증하였다 고 응답하였고, 그 중 20-40명의 결과를 이용하여 검증한 기관 의 수가 가장 많았다(80.0\%-92.9\%).

\section{5. 내부정도관리}

1) 정도관리물질

대부분의 기관에서 각 호르몬검사 시 매 검사마다 2 개 이상 의 정도관리물질을 이용하고 있었으며, 2 개의 정도관리물질을 이용하는 기관이 가장 많았으나, 1기관에서는 시행하는 모든 호르몬검사의 정도관리물질을 1 개만 이용하고 있었고, 다른 1 기관에서는 prolactin검사 시 정도관리물질을 1 개만 이용하고 있었다(Fig. 2A).

호르몬검사를 시행하는 것으로 응답한 모든 기관은 상품화 된 정도관리물질을 이용하고 있었고, third party 물질 등 정 도관리물질을 추가로 이용하는 기관이 1 기관 있었다. 호르몬 별로 기관들에서 응답한 상품화된 정도관리물질의 회사명의 분포는 Fig. 3A와 같았다. Testosterone과 estradiol의 경우 미국 $\mathrm{CDC}$ 에서는 참고물질(reference material)을 제공하면 서 인증제도(certification program)를 운영하고 있으나[1], 국내 검사실 중 미국 $\mathrm{CDC}$ 에서 제공하는 참고물질을 내부정도 관리에 이용하는 기관은 없었다.

\section{2) Calibrator}

호르몬검사를 시행하는 것으로 응답한 기관 중 1 곳을 제외 한 모든 기관은 매 검사 시 2 개 이상의 calibrator를 사용하고 있었다. 1 개의 기관은 시행하는 모든 호르몬검사 종목에 대 해 calibrator를 1 개만 사용하고 있었으며, 다른 1 개의 기관은 testosterone검사 시 calibrator를 1 개 사용하고 있었다. 응답 한 기관 중 2 개의 calibrator를 이용하는 것으로 응답한 기관이 가장 많았으며, $11.1 \%-30.5 \%$ 의 기관은 4 개 이상의 calibrator 를 이용하는 것으로 보고하였다(Fig. 2B).

호르몬검사를 시행하는 기관 중 1 곳을 제외한 모든 기관 은 상품화된 calibrator를 사용하고 있었고, 1 개의 기관에서 는 LH검사를 위한 calibrator로 환자 검체를 사용하는 것으 로 보고하였다. 각 호르몬별 각 기관에서 응답한 상품화된 calibrator 물질의 제조사 분포는 Fig. $3 \mathrm{~B}$ 와 같다. 
A

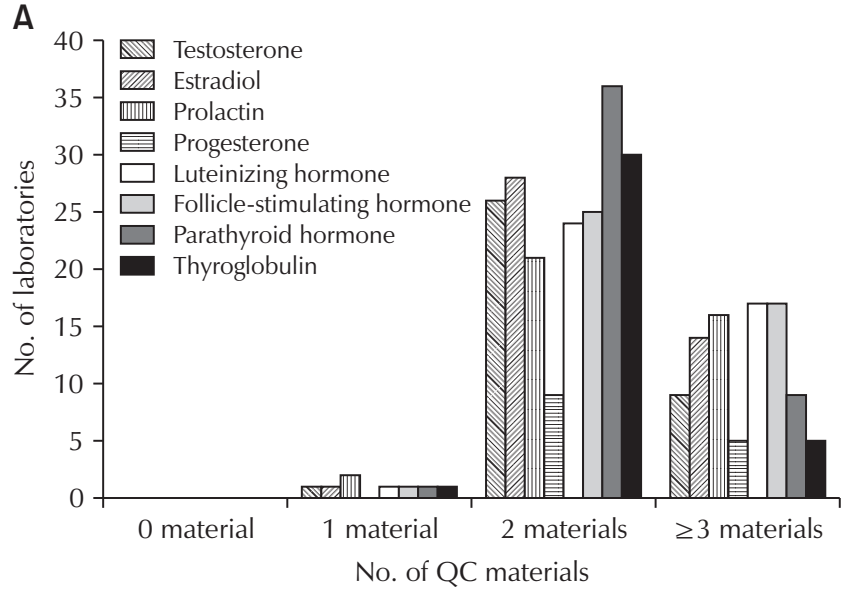

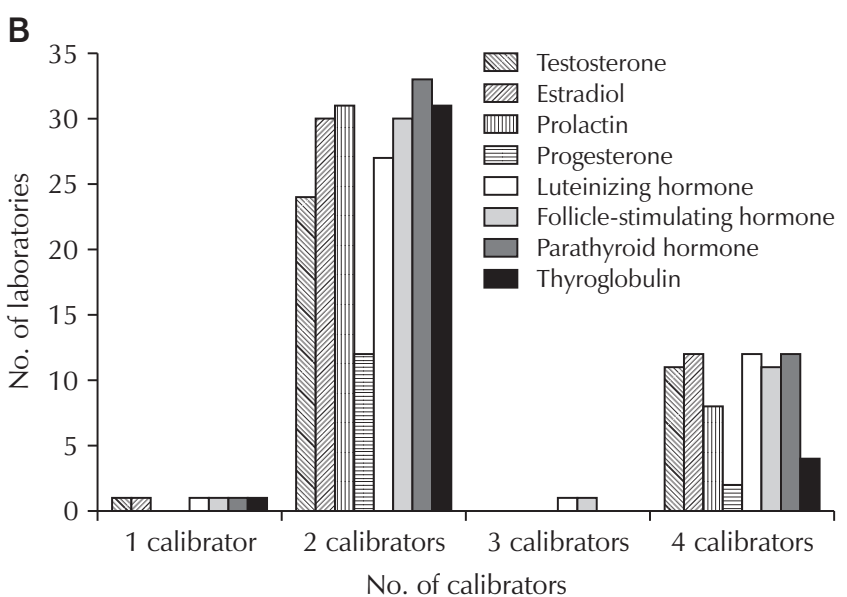

No. of calibrators

Fig. 2. Numbers of QC materials (A) and calibrators (B) used for each hormone test. Abbreviation: QC, quality control.
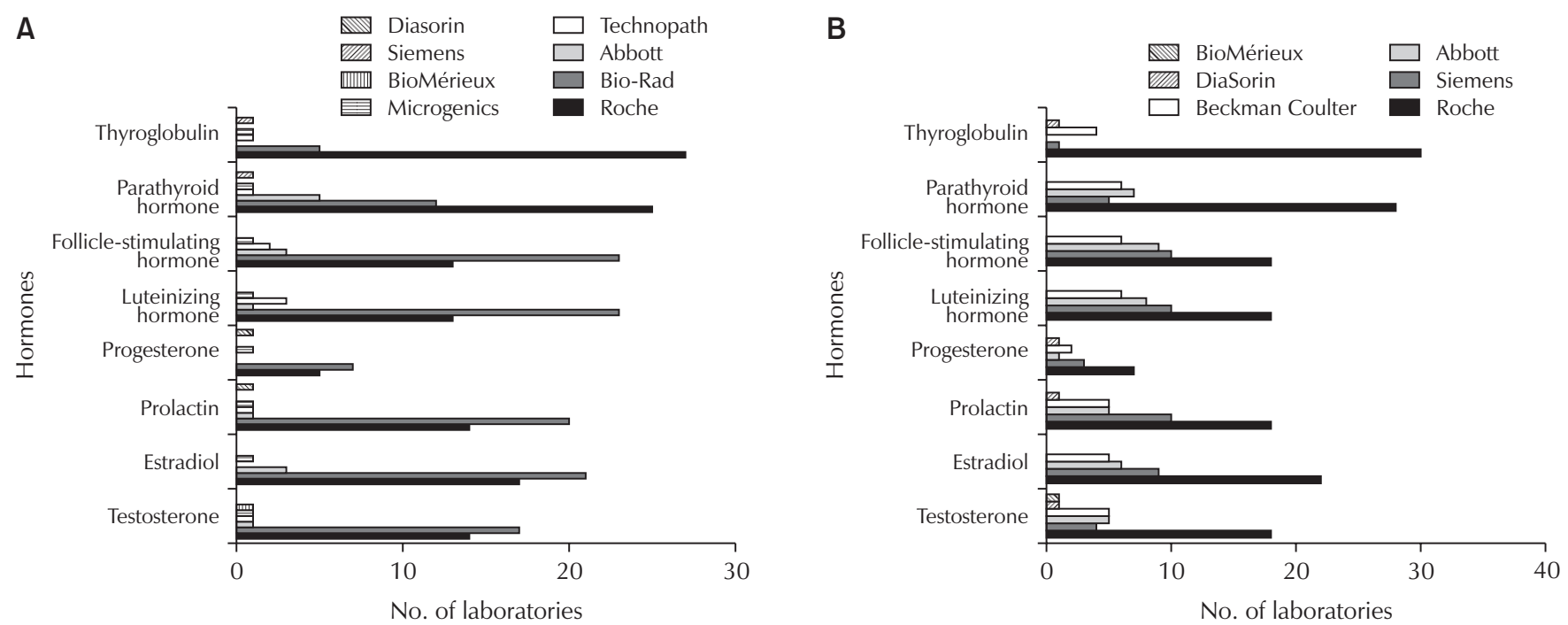

Fig. 3. Manufacturers of quality control materials (A) and calibrator materials (B) used for hormone analyses in surveyed clinical laboratories. The following test was used: DiaSorin (Stillwater, MN, USA), Simens (Tarrytown, NY, USA), BioMérieux (Marcy l'Etoile, France), Microgenics (Fremont, CA, USA), Technopath (Dublin, Ireland), Abbott (Abbott Park, IL, USA), Bio-Rad (Hercules, CA, USA), Roche (Mannheim, Germany), and Beckman Coulter (Brea, CA, USA).

\section{3) 시약}

호르몬검사를 시행하는 것으로 응답한 모든 기관은 전용 시 약을 사용하고 있었다. 시약의 변경 시 기존 시약과의 비교를 위해서 응답한 모든 기관은 시약의 변경 시 기존 시약과의 비 교를 위해 환자 검체, 정도관리물질, 또는 기타 물질을 이용하 는 것으로 보고하였다. 응답한 기관 중 4 개의 기관에서는 해당 기관에서 시행하는 호르몬검사 종목에 대해 시약의 변경 시 기 존 시약과의 비교를 위해 정도관리물질만 이용하고 환자 검체 를 이용하지 않는다고 응답하였다.

\section{6. 외부정도관리}

호르몬검사를 시행하는 것으로 응답한 모든 기관은 1 가지 이상의 외부정도관리방법 또는 그 대체방법을 이용하여 외부 정도관리를 시행하고 있었다(Table 3). Estradiol은 2기관, thyroglobulin은 1기관을 제외한 나머지 모든 기관들이 대한 임상검사정도관리협회에서 시행 중인 외부정도관리 프로그 램에 참여하고 있었다. LH와 FSH, parathyroid hormone은 $56.5 \%-66.7 \%$ 의 기관들이 국내 외부정도관리 프로그램에 참 여하지 않는다고 응답하였다. 
Rihwa Choi et al • Survey of Hormone Tests

Table 3. Proficiency tests or external quality assurance methods used to evaluate hormone analyses in surveyed laboratories

\begin{tabular}{|c|c|c|c|c|c|c|c|c|c|}
\hline \multirow[t]{2}{*}{ Variable } & \multirow[t]{2}{*}{$\begin{array}{c}\text { Total } \\
\text { no. }\end{array}$} & \multicolumn{2}{|c|}{ PT by KAEQAS } & \multicolumn{2}{|c|}{ CAP PT } & \multicolumn{2}{|c|}{$\begin{array}{c}\text { Split sample } \\
\text { analysis with other } \\
\text { laboratories }\end{array}$} & \multicolumn{2}{|c|}{ Other method } \\
\hline & & Yes & No & Yes & No & Yes & No & Yes & No \\
\hline Testosterone & 36 & 36 & 0 & 14 & 21 & 4 & 32 & 0 & 33 \\
\hline Estradiol & 43 & 41 & 2 & 14 & 29 & 8 & 35 & 0 & 42 \\
\hline Luteinizing hormone & 42 & 14 & 28 & 13 & 29 & 25 & 17 & 2 & 39 \\
\hline Follicle-stimulating hormone & 43 & 15 & 28 & 12 & 31 & 26 & 17 & 2 & 40 \\
\hline Parathyroid hormone & 46 & 18 & 26 & 13 & 33 & 26 & 20 & 1 & 43 \\
\hline Thyroglobulin & 36 & 35 & 1 & 12 & 24 & 6 & 30 & 0 & 35 \\
\hline
\end{tabular}

Abbreviations: PT, proficiency test; KAEQAS, Korean Association of External Quality Assessment Service; CAP, College of American Pathologists.

${ }^{\star}$ External quality assurance service conducted by Bio-Rad (via website; Bio-Rad Laboratories, Hercules, CA, USA).

\section{고찰}

국내 임상검사실에서는 조사대상 8 종 호르몬의 검사 시 매 우 다양한 검사장비를 이용하고 있어, 검사장비 간 결과 차이 에 대한 일치화(harmonization) 노력이 필요할 것으로 생각 하였다. 미국 College of American Pathologists에서 제공하 는 정확도 기반 proficiency test 프로그램에 참여한 국제적인 검사실들의 결과에 의하면 testosterone과 estradiol의 경우, 참고 측정법인 액체 크로마토그래피 질량분석법과 비교하였 을 때, 일부 측정법은 체계적 오차(systemic bias)가 있는 것 으로 확인되어 더 나은 일치화를 위하여 지속적인 노력이 필요 한 것을 보고하였다[2].

국내 임상검사실의 각 장비 간 보고소요시간에 대한 분석에 서는 응답한 $13.9 \%-26.1 \%$ 의 기관만이 2 시간 이내 보고를 완 료하고 있어 보고소요시간이 긴 기관에서 호르몬검사를 진료 전 검사로 이용하기 위하여는 더욱 노력이 필요할 것으로 생각 되었다.

결과 보고단위에 대한 분석에서 특히 testosterone은 사용 하는 단위가 매우 다양할 뿐 아니라 conventional unit이나 SI unit이 아닌 다른 보고단위를 이용하는 기관이 $83.4 \%$ 에 달하였 으므로 일치화에 대한 노력이 필요하며, 검사실 간 결과값을 비 교하고자 할 때에 특별히 주의가 필요할 것으로 생각하였다[3].

보고범위에 대한 분석에서 각 호르몬검사마다 국내 임상검 사실들의 보고범위는 매우 다양하였다. 특히 estradiol의 경우, 국내 임상검사실들의 보고범위의 차이가 컸다. Estradiol의 참 고범위는 사춘기 전 소아(prepubertal children) 및 폐경 여성 (postmenopausal)에서 $20 \mathrm{pg} / \mathrm{mL}$ 를 보일 수 있는 것으로 알
려져 있는데, 일부 기관에서는 임상 보고범위의 하한이 $20 \mathrm{pg} /$ $\mathrm{mL}$ 이어서 해당 기관은 임상 보고범위의 하한을 더 낮추는 등 참고범위의 재검토가 필요할 것으로 생각되었다[3].

참고범위의 경우, 성별 또는 연령에 따라 구분된 참고범위 를 제시하는 기관들이 많았는데, 대부분의 기관들이 외부 참 고범위를 도입하여 사용 중이었다. 참고범위를 자체 설정하는 일부 기관들 중 1 기관에서는 119 명 이하의 결과값을 이용하여 설정하였다고 하였는데, Clinical \& Laboratory Standards Institute (CLSI) guidelines EP28-A3인 “Defining, establishing, and verifying reference intervals in the clinical laboratory: approved guideline"에서는 $90 \%$ 의 신뢰 구간(confidence interval)을 위해서 적어도 120 명의 결과가 필요한 것으로 제시하고 있다[4].

호르몬검사의 내부정도관리에서는 정도관리물질을 1 개만 사용하는 기관이 있었는데, 대한진단검사의학회/진단검사의 학재단에서 시행하는 우수검사실 신임인증 심사점검표 중 임 상화학 분야에서는 정도관리물질을 최소 2 가지 농도 이상 사 용할 것을 권고하며, 1 가지만 이용할 때에는 감점하고 있으므 로, 해당 기관에서는 참고하여 질 향상을 위한 노력이 필요할 것으로 생각하였다[5].

시약의 경우 4 개의 기관에서는 호르몬검사 시약의 변경 시 기존 시약과의 비교를 위해서 정도관리물질만 이용하 고 환자 검체를 이용하지 않는다고 응답하였다. 2013 CLSI guideline EP26-A인 "User evaluation of between-reagent lot variation: approved guideline” [6]에서는 표준물질이나 정도관리물질은 환자 검체와 기질(matrix)이 다르기 때문에 단독으로 사용하지 않고 환자 검체를 함께 사용해야 한다고 기 
술하고 있다. 대한진단검사의학회/진단검사의학재단에서 시 행하는 우수검사실 신임인증 심사점검표 중 임상화학항목에 서는 적절한 수의 환자 검체를 사용하는 것을 원칙으로 하되, 환자 검체를 구할 수 없거나 환자 검체에서 불안정한 종목은 표준물질이나 정도관리물질을 사용할 수 있는 것으로 제시하 고 있으므로 참고가 필요할 것으로 생각되었다[5].

호르몬검사는 이질적인 검사방법들 간뿐만 아니라 동일한 검사방법 내에서도 측정 장비나 시약 kit에 따라 검사결과가 다양하여 정확도나 정밀도 등 검사성능에 대한 문제 제기가 다 양하게 보고되고 있으므로 내부 및 외부 정도관리가 중요하다 〔1]. 대한임상검사정도관리협회에서 시행 중인 외부정도관리 프로그램이 있음에도 불구하고 본 설문에 참여한 기관들의 절 반 이상이 LH와 FSH, parathyroid hormone의 외부정도관리 프로그램에 참여하지 않는다고 응답하였는데, 국내 외부정도 관리 프로그램을 적극적으로 활용할 필요가 있을 것으로 생각 되었다. Testosterone과 estradiol의 경우 미국 $\mathrm{CDC}$ 에서는 참 고물질(reference material)을 제공하면서 정확도기반 인증프 로그램(Laboratory Quality Assurance and Standardization Program-CDC Laboratory/Manufacturer Hormone Standardization Program certification program)을 운영하 고 있지만[1], 국내 임상검사실 중 이 프로그램을 이용하는 기 관은 없는 것으로 파악되었다. 국내에서는 일부 임상화학검사 들에 대해 정확도 기반의 외부정도관리 프로그램을 운영 중인 데, 호르몬검사 분야로 확대될 수 있다면 여러 검사실에서 관 심을 가질 수도 있을 것이라 생각한다.

본 설문조사에 포함되어 있지는 않았지만, 추후 국내 임상검 사실에서 호르몬검사에 사용하는 주요 시약들의 traceability (소급성)에 대한 현황조사가 이루어진다면 호르몬검사의 질 항상을 꾀하는 데 도움이 될 것이라 생각된다.

요약하면, 설문조사를 통하여 국내 임상검사실에서 시행 중 인 8종류의 호르몬검사현황에 관한 기초자료를 수집하였으며, 이 자료가 향후 각 검사실에서 호르몬검사의 질 향상을 위한
참고자료로 활용되어 질 향상을 위한 개선방안과 호르몬검사 가이드라인을 도출하는 데 이용될 수 있기를 기대한다.

\section{감사의 글}

이 논문은 대한임상검사정도관리협회 2016년 학술연구비 지원에 의해 이루어진 것이다.

\section{REFERENCES}

1. Vesper HW, Botelho JC, Shacklady C, Smith A, Myers GL. CDC project on standardizing steroid hormone measurements. Steroids 2008;73:1286-92.

2. College of American Pathologist. Education discussion: accuracy based testosterone and estradiol: 2016-A. Northfield (IL): College of American Pathologist, 2016.

3. Burtis CA, Ashwood ER, Bruns DE. Tietz textbook of clinical chemistry and molecular diagnostics. St. Louis (MO): Elsevier Saunders, 2012.

4. Horowitz GL, Altaie S, Boyd JC, Ceriotti F, Garg U, Horn P. Defining, establishing, and verifying reference intervals in the clinical laboratory: approved guideline: CLSI C28-A3. Wayne (PA): Clinical and Laboratory Standards Institute, 2010.

5. Korean Society for Laboratory Medicine, Laboratory Medicine Foundation. Clinical Laboratory Accreditation Program checklist in Korea: clinical chemistry. Seoul: Korean Society for Laboratory Medicine, 2016.

6. Person NB, Budd J, de Vore K, Durham A, Genta $\mathrm{V}$, Huang S. User evaluation of between-reagent lot variation: approved guideline: CLSI Ep26-A. Wayne (PA): Clinical and Laboratory Standards Institute, 2013. 


\section{국내 진단의학검사실의 8종 호르몬 측정법에 대한 실태조사} 최리화 ${ }^{1,2}$ - 박형두

${ }^{1}$ 성균관대학교 의과대학 삼성서울병원 진단검사의학과, ${ }^{2}$ 녹십자의료재단

배경: 국내 임상검사실에서 시행 중인 8종 호르몬(테스토스테론, 에스트라디올, 프로락틴, 프로게스 테론, 황체형성호르몬, 여포형성호르몬, 부갑상선호르몬, 갑상선글로불린) 검사현황을 알아보고자 하였다.

방법: 2016년 11월 1일부터 12월 31일까지 대한임상검사정도관리협회의 300개 회원기관을 대 상으로 8종 호르몬검사에 관한 설문조사를 시행하여 회신결과를 분석하였다. 설문은 8종 호르몬의 측정에 사용되는 검사방법, 검사장비, 월간 검사 건수, 목표 보고소요시간, 결과 보고단위, 보고범

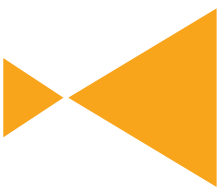

Journal of

LABORATORY MEDICINE

and

QUALITY ASSURANCE

위, 참고범위, 내부 및 외부 정도관리방법 등에 대한 내용을 포함하였다.

결과: 설문에 응답한 54기관(18\%)으로부터 받은 자료를 분석하였다. 회신기관은 호르몬 측정을 위 해 다양한 검사방법 및 장비, 상업용 키트를 사용하고 있었으며, 윌별 검사 건수 및 보고소요시간이 다양하였다. 항목별로 보고단위도 여러 가지를 사용했는데, 특히 테스토스테론의 검사실 간 보고단 위가 다양하였다. 대부분의 검사기관들은 외부의 참고범위를 검증하는 방법을 이용하였다. 황체형 성호르몬과 여포형성호르몬, 부갑상선호르몬의 경우 대한임상검사정도관리협회에서 제공하는 외 부정도관리 프로그램에 참여하지 않는 기관이 많았다.

결론: 국내 임상검사실의 호르몬검사 현황을 조사한 이번 연구자료가 향후 각 검사실에서 호르몬 검사의 질 향상을 유도하고 호르몬검사 가이드라인을 도출하는 데 유용하게 이용될 수 있기를 기 대한다.

(J Lab Med Qual Assur 2017;39:124-131) 